\title{
LAS POLÍTICAS ANTICORRUPCIÓN EN LA EMPRESA
}

[Anticorruption policies in the company]

\author{
Percy García Cavero*
}

\begin{abstract}
RESUMEN
El presente artículo aborda el deber de las empresas de adoptar internamente un sistema de cumplimiento normativo en materia anticorrupción. En primer lugar, se hace un análisis de los factores más relevantes que han dado lugar al surgimiento de este deber, a partir de los cuales se podrá precisar también cómo está concretamente configurado. Por otro lado, se entra en aspectos operativos del compliance anticorrupción, cuyo cumplimiento autoriza a calificarlo de idóneo y, por lo tanto, a dar por cumplido el deber de la empresa de estar correctamente organizada.

\section{Palabras clave}

Corrupción - responsabilidad penal de la persona jurídica - FCPA - compliance - análisis del riesgo administración del riesgo
\end{abstract}

\section{ABSTRACT}

This article addresses the corporate duty of implementing an internal regulation system for anti-corruption compliance. Firstly, the most important factors that caused this duty to come into existence, which will in turn allow us determine the way it is organized, are analyzed. Secondly, the article focuses on anti-corruption compliance operational aspects, fulfillment of which characterizes it as a proper element and, therefore, it can be considered that the corporate's duty of being properly organized has been accomplished.

\section{KeYwORDS}

Corruption - criminal liability of the corporate body - FCPA - compliance risk analysis - risk management

ReCIBIDO el 10 de junio y APROBADO el 30 de octubre de 2016

* Doctor en Derecho, Profesor Ordinario Principal de Derecho Penal en la Universidad de Piura (Perú), percy.garcia@udep.pe 


\section{INTRODUCCIÓN}

Hasta hace unos años, la corrupción era vista fundamentalmente como un asunto de funcionarios públicos ímprobos que ponían a disposición su función pública a cambio de una ventaja o beneficio indebido ${ }^{1}$. Sobre la base de este enfoque, la política criminal desplegada para enfrentarla, cargaba su respuesta sobre el funcionario público. A nivel de la represión penal era notoria la mayor penalidad con la que se castigaba al funcionario público en comparación con el agente corruptor. Es más, la reacción penal contra el agente corruptor llegaba incluso a neutralizarse en el plano criminológico, bajo la idea de que no había otra forma de hacer negocios ${ }^{2}$. La intensificación de la respuesta penal contra el funcionario público no se quedó en la mayor severidad de la pena, sino que se tomaron otras medidas adicionales, como la configuración de tipos penales aligerados en los elementos de difícil probanza (colusión desleal, negociación incompatible o enriquecimiento ilícito), la ampliación del plazo de prescripción de los delitos cometidos por funcionarios públicos o la imposición siempre efectiva de las penas privativas de libertad impuestas a funcionarios públicos. A nivel preventivo, las medidas adoptadas se centraron igualmente en el accionar del funcionario público, tal como lo demuestra, por ejemplo, el establecimiento de deberes de declaración anual de bienes, la creación de mayores mecanismos e instituciones de control de la función pública o la implementación de procesos sancionatorios con un estándar probatorio bastante flexible.

La situación anteriormente descrita ha ido cambiando de forma notoria en los últimos tiempos. La corrupción es ahora claramente una cosa de dos, por lo que la actuación del particular es considerada igual de grave que la del funcionario público corrupto. Este descubrimiento del particular en la génesis de la corrupción ha repercutido tanto en su represión, como en su prevención. A nivel represivo, el proceder del agente corruptor ha adquirido una independencia valorativa para el Derecho penal, lo que ha dado lugar al surgimiento de nuevas figuras delictivas centradas únicamente en

${ }^{1}$ Vid., Nieto Martín, Adán, La privatización de la lucha contra la corrupción, en Arroyo Zapatero, Luis - Nieto Martín, Adán (directores), El Derecho penal económico en la era del compliance (Valencia, Tirant lo Blanch, 2013), p. 191.

${ }^{2}$ La expresión más clara de esta neutralización se dio en las legislaciones tributarias de algunos países europeos que admitieron la posibilidad de desgravación fiscal de los sobornos que las empresas "tenían" que pagar para proteger su inversión en países en vías de desarrollo. Vid., al respecto, Nieto MarTín, Adán, La prevención de la corrupción, en Nieto MarTín, Adán (dir.), Manual de cumplimiento penal en la empresa (Valencia, Tirant lo Blanch, 2015), p. 318. 
el acto corruptor del particular. El llamado cohecho activo transnacional, por ejemplo, castiga el acto de corrupción aunque recaiga sobre funcionarios extranjeros que no forman parte de la Administración Pública, cuyo correcto funcionamiento es protegido por las leyes penales nacionales. Lo mismo cabe decir respecto de la criminalización de la corrupción privada, la que parte de la idea de que el acto corruptivo del privado no sólo puede tener lugar en relación con la Administración Pública, sino también con otros particulares. En el plano preventivo, las medidas adoptadas se cargan ahora también sobre el particular. Esto se puede ver fácilmente, por ejemplo, con la creación del sistema de listas negras que impide a la Administración contratar con empresas que hayan sido sancionadas por actos de corrupción. Pero quizá la mayor expresión de una prevención centrada en el particular es la asignación de deberes de contribuir en la lucha contra la corrupción. De manera concreta, a las empresas se les exige hoy en día adoptar medidas internas de prevención de la corrupción y ayudar a los órganos de persecución penal a la investigación de los casos de corrupción detectados.

La presente contribución se va a ocupar precisamente de lo último que se acaba de decir sobre la prevención de la corrupción enfocada en el particular, esto es, la elaboración de las políticas anticorrupción por parte de la empresa. El abordaje de esta cuestión se hará dividiéndola en dos partes. Una primera parte, que podría ser calificada como de legitimación, estará dirigida a determinar cómo se ha ido configurando jurídicamente la obligación de las empresas de adoptar un sistema de prevención de la corrupción de los funcionarios públicos. La segunda parte tiene un carácter mucho más operativo y, por ello, se encargará de definir los pasos que una empresa debe de dar para adoptar un compliance anticorrupción idóneo.

\section{LA OBLIGACIÓN DE LAS EMPRESAS DE ADOPTAR UN SISTEMA} DE PREVENCIÓN DE LA CORRUPCIÓN PÚBLICA

En la actualidad, resulta cada vez más nítida la obligación que recae sobre las empresas de contribuir a la lucha contra la corrupción mediante la adopción de mecanismos internos dirigidos a prevenir o, en todo caso, detectar las conductas de sus miembros individuales o de terceros vinculados dirigidas a corromper a funcionarios públicos. El surgimiento de esta obligación es producto de la conjunción de varios factores de distinta procedencia, a saber: i) el consenso internacional sobre la necesidad de reprimir los actos de corrupción de funcionarios públicos realizados por las empresas, al ser un factor de grave distorsión de la competencia en mercados globalizados o unificados; ii) el principio del buen gobierno corporativo 
de las empresas consistente en controlar sus riesgos de infracción legal por medio de la adopción de programas de cumplimiento normativo; y iii) la tendencia legislativa de regular la responsabilidad penal de las personas jurídicas en países deudores del sistema continental europeo sobre la base de una defectuosa organización expresada en la ausencia de un programa de cumplimiento normativo idóneo.

\section{La Foreing Corrupt Practices Act de 1977 (FCPA)}

Después de la II Guerra Mundial, la corrupción de funcionarios públicos se convirtió en una actividad usual de las empresas trasnacionales para proteger sus inversiones en países con escasa o nula seguridad jurídica ${ }^{3}$. Esa era la manera de hacer negocios asumida sin mayor controversia por casi todas las empresas con inversión en los nuevos países. Sin embargo, en la década de los setenta del siglo pasado se inició en los EE.UU. una corriente de opinión dirigida a cambiar este orden de cosas, impulsado sobre todo por graves escándalos políticos como el caso Watergate, en el que se destapó, entre otras cosas, el financiamiento ilegal al partido republicano y el pago de coimas a gobiernos extranjeros para proteger las inversiones 4 .

Es así que en 1977 ve la luz la FCPA, en la que se toma la decisión de responsabilizar penalmente a las empresas que listan en una bolsa de valores americana (issuers) o desarrollan su actividad principal en los EE.UU. (domestic concerns) por la realización de actos de corrupción a funcionarios públicos extranjeros. La prohibición penal alcanzó a sus trabajadores ciudadanos o residentes. Esta orientación punitiva no se sustentó únicamente en un reexamen ético a la manera cómo las empresas americanas hacían negocios en el extranjero, sino también en el convencimiento de que tal forma de proceder generaba una situación de competencia desleal en relación con aquellas empresas que no optaban por el camino de la corrupción, además de un peligro no advertido a los inversionistas en relación con el manejo de su inversión. La fuerza innovadora de la FCPA no se tradujo, sin embargo, en su vigencia efectiva. Se tuvieron que superar ciertos limitantes surgidos del mismo tenor de la normativa.

Una de las paradojas de la normativa americana de represión de la corrupción internacional era que buscaba fomentar la competencia por medio de la erradicación de la corrupción como la forma más eficiente de hacer negocios, pero resultaba que, al margen de la persecución, quedaban las empresas radicadas en el extranjero, lo que era, a su vez, una indebida

${ }^{3}$ Nieto Martín, Adán, cit. (n. 1), p.193.

${ }^{4}$ Carrión Centeno, Andy, Criminal Compliance (Lima, Thomson Reuters, 2014), p. 20. 
situación de ventaja competitiva para estas últimas. Esta fragmentariedad persecutoria ha ido cambiando a partir de la década de los noventa del siglo pasado con el impulso de acuerdos internacionales de lucha contra la corrupción en los negocios por parte de importantes organismos internacionales como la OEA, la ONU o la OCDE, logrando que muchos países (incluidos los países receptores de las inversiones) se sumen a la cruzada mundial contra la corrupción. A lo anterior debe sumarse que la International Antibribery and Fair Competition Act de 1998, amplió el círculo de destinatarios de la FCPA, abarcando también a las empresas nacionales o residentes que actúen fuera de los EE.UU.

La vaguedad de las disposiciones de la FCPA fue otro de los limitantes para su aplicación. Este problema fue superado una vez que el Departamento de Justicia (DOJ) empezara a finales de los noventa a establecer por medio de los llamados memorándums los criterios para que la fiscalía aplique la FCPA (memorándums Holder, Thompson, McNulty, Filip, Yates) $)^{5}$. En consonancia con la US Federal Sentencing Guidelines for Organisations Offenders de 1991, uno de los puntos más importantes de la fijación de criterios por parte del DOJ fue la posibilidad de posponer o impedir el proceso judicial por los delitos de corrupción en función de la existencia o implementación de un programa de cumplimiento promovido por la dirección de la empresa. Con ello se dio origen a la tendencia, hoy ampliamente extendida, de involucrar a las empresas en la lucha contra la corrupción por medio de incentivos para adoptar sistemas de cumplimiento normativo en materia anticorrupción ${ }^{6}$.

\section{El corporate compliance}

Desde la primera mitad del siglo pasado se tiene como un dato cierto que las empresas son el principal foco de creación de riesgos por su notoria preponderancia en los diversos sectores sociales ${ }^{7}$. Ante este panorama es lógico que el Estado, en tanto garante del bien común, se vea en la necesidad de establecer mecanismos adecuados de control para asegurar que

5 Vid., los detalles en Carrión Centeno, Andy, cit. (n. 4), pp. 34 s.

${ }^{6}$ Nieto Martín, Adán, cit. (n. 1), pp. 195 s.

7 Así, Nieto MarTín, Adán, Responsabilidad social, gobierno corporativo y autorregulación: sus influencias en el derecho penal de la empresa, en Polit. crim. 5 (2008) A3-5, p. 1, hace referencia a lo que algunos llaman neocorporativismo para graficar el hecho de que las corporaciones, y no los agentes económicos individuales, ocupan el papel hegemónico en la sociedad. Vid., igualmente, Maroto Calatayud, Manuel, Liberalismo versus neocorporativismo: Los discursos de la autorregulación como discursos legitimantes, en Arroyo, Luis - Lascano, Carlos - Nieto, Adán (dir.), Derecho penal de la empresa (Buenos Aires, Ediar, 2012), p. 421. 
su accionar no traiga consigo consecuencias socialmente dañosas o, en todo caso, reducirlas a niveles tolerables. El aseguramiento de los riesgos provenientes de las empresas se pretende conseguir por medio de diversos modelos que pendulan entre dos extremos claramente definidos. En una punta se encuentra el modelo que, por medio de un intervencionismo puro, asigna al Estado la labor de definir los mecanismos de prevención que la empresa debe adoptar, supervisar su implementación y sancionarla en caso de incumplimiento (el modelo del comando y control) ${ }^{8}$. En la otra punta se coloca la visión absolutamente liberal de dejar en sus manos la decisión de incorporar las medidas de aseguramiento de los riesgos en función de las exigencias del mercado (el modelo de la autorregulación) ${ }^{9}$.

Luego de una disputa de varias décadas ${ }^{10}$, puede decirse que en la actualidad reina el consenso de que los extremos antes mencionados resultan impracticables. El primero por la imposibilidad del Estado para entrar a regular y controlar eficazmente aspectos que dependen de factores tan disímiles como las dimensiones de cada empresa o las características particulares de los sectores del mercado en los que realizan sus operaciones ${ }^{11}$; el segundo por el dato de la experiencia sobre la poca prioridad que la dirección de la empresa le suele asignar a este tema en comparación con otros que le parecen más importantes para sus intereses económicos ${ }^{12}$. Por ello, desde los años noventa del siglo pasado se han ido consolidando modelos intermedios de aseguramiento de los riesgos empresariales, siendo el más reconocido el modelo de la autorregulación regulada ${ }^{13}$. Este modelo

8 Vid., Coca Vila, Ivó, ¿Programas de cumplimiento como forma de autorregulación regulada?, en Silva SÁNCHEZ, Jesús María (dir.), Criminalidad de empresa y Compliance (Barcelona, Atelier, 2013), p. 44.

9 Resulta conveniente precisar que la autorregulación no debe entenderse como un retroceso del Estado en la función reguladora (desregulación), sino, paradójicamente, como expresión de una regulación más rigurosa y eficaz. Vid., al respecto, Esteve Pardo, José, Autorregulación: Génesis y efectos (Navarra, Aranzadi, 2002), p. 27 y ss.

${ }^{10}$ Nieto Martín, Adán, cit. (n. 7), p. 3, destaca el enfrentamiento de estas dos visiones en la década de los treinta del siglo pasado y cómo han evolucionado en Europa y en los Estados Unidos de Norteamérica.

${ }^{11}$ Vid., Gómez-Jara Díez, Carlos, Fundamentos de la responsabilidad penal de las personas jurídicas, en BAJO, Miguel - FeIJOO, Bernardo - GOMEZ-JARA, Carlos, Tratado de responsabilidad penal de las personas jurídicas (Madrid, Aranzadi, 2012), p. 114. Hace mención a razones de complejidad, internacionalidad y presupuestales, CoCA VILA, Ivó, cit. (n. 8), p. 45 y s.

12 Similarmente, EngelHart, Marc, Sanktionierung von Unternehmen und Compliance, 2a ed., (Berlin, Duncker \& Humblot 2012), p. 605.

13 Vid., Nieto Martín, Adán, cit. (n. 7), p. 3 y s.; Engelhart, Marc, cit. (n. 12), p. 645 y ss. 
apunta a generar las condiciones para que las corporaciones adopten, por medio de una coordinación con los poderes públicos y otros agentes sociales $^{14}$, ciertas normas de comportamiento idóneas para evitar o mitigar los riesgos y ellas mismas se encarguen, a su vez, de asegurar su efectivo cumplimiento $^{15}$. Se trata de un modelo regulatorio que parte de la autorregulación de las empresas ${ }^{16}$, pero que se hace de manera subordinada a unos fines o intereses predeterminados por el Estado ${ }^{17}$ y sujeto también a su supervisión. No tiene lugar, por tanto, una ausencia del Estado, sino, más bien, una presencia más eficaz por medio de un mecanismo de control con un nivel mayor de sofisticación ${ }^{18}$.

El modelo de autorregulación regulada requiere reforzar la ética de las empresas para que éstas se decidan por si mismas a controlar sus riesgos. La consecución de esta exigencia se corresponde con el esfuerzo emprendido en la década de los noventa por diversos organismos internacionales de carácter económico para incorporar un componente ético en la actuación empresarial (business ethics) y superar, así, una visión de la empresa informada por lo puramente económico ${ }^{19}$. Desde entonces se ha adoptado en el lenguaje empresarial ordinario el término "responsabilidad social corporativa" (corporate social responsibility) para dar mayor concreción a la idea de dotar de valores éticos a las empresas. Lo que se procura es conseguir que las entidades empresariales se muevan, por si mismas, a desarrollar ciertas actividades en favor de otros una vez que llegan a identificarse con el entorno social en el que llevan a cabo sus operaciones. Estas actividades van desde el cumplimiento de ciertos estándares de orden laboral, pasando por el respeto de los derechos humanos y la preservación de la calidad

${ }^{14}$ Así, Nieto Martín, Adán, La responsabilidad penal de las personas juridicas: Un modelo legislativo (Madrid, Iustel, 2008), p. 176 y s., se refiere a una regulación cooperativa o tripartismo.

15 Vid., Nieto Martín, cit. (n. 7), p. 4; Darnacullta i Gardella, Mercé, $A u$ torregulación y Derecho Público: La autorregulación regulada (Madrid, Marcial Pons, 2005), p. 87.

${ }^{16}$ Así, Coca Vila, Ivó, cit. (n. 8), p. 48, en relación con lo que llama autorregulación pura o voluntaria.

17 Vid., Coca Vila, Ivó, cit. (n. 8), p. 51. Cuánto debe precisar el Estado, se deja a su criterio según las necesidades de política jurídica, vid., ENGELHART, Marc, cit. (n. 12) p. 647.

${ }^{18}$ Así, Nieto Martín, Adán, cit. (n. 7), p. 4; Coca Vila, Ivó, cit. (n. 8.), p. 47.

19 Sobre la ética de los negocios y la importancia que cada vez más se le reconoce en el mundo empresarial, HefEndeHL, Roland, Corporate Governance und Business Ethics: Scheinberuhigung oder Alternativen bei der Bekämpfung dr Wirtschaftskriminalität?, en JZ3 (2006), p. 121 y s. Igualmente, THEILE, Hans, Unternehmensrichtlinien - ein Beitrag zur Prävention von Wirtschaftskriminalität?, en ZIS 9 (2008), p. 406. 
medioambiental, llegando hasta una relación responsable con terceros interesados como los socios, los proveedores, los clientes y la comunidad en general ${ }^{20}$.

Uno de los ámbitos específicos de la responsabilidad social corporativa en relación con los terceros interesados está referido a la transparencia de la empresa frente a los inversionistas que no se ocupan de su administración (stakeholders). Dado que en la empresa moderna la propiedad y la gestión se encuentran por lo general separadas, como lo pone de manifiesto, por ejemplo, el sistema de cotización de acciones en bolsa, resulta necesario asegurar un nivel de transparencia en la conducción de la empresa que permita a los inversionistas tener un cabal conocimiento de los riesgos que asumen con su inversión. Esto se ha procurado alcanzar con lo que se conoce como el buen gobierno corporativo (good corporate governance $)^{21}$, lo que se ha traducido operativamente en la elaboración de principios o códigos que establecen determinados estándares en la dirección y supervisión de la empresa que deben implementarse para garantizar una administración ordenada y confiable ${ }^{22}$. Dentro de los estándares del buen gobierno corporativo, cabe destacar la necesidad de incorporar en la empresa una cultura del cumplimiento que asegure la observancia de la ley por medio de medidas de prevención y detección de las infracciones legales (corporate compliance).

Con el compliance se garantiza a los inversionistas o a cualquier otra persona que quiera vincular sus intereses económicos a la gestión exitosa de una empresa, que los riesgos de ver a la empresa inmersa en una disputa o conflicto judicial se encuentran de alguna manera controlados por un programa de cumplimiento normativo. Si bien las empresas no están obligadas legalmente a adoptar un compliance, la actuación ética frente a los terceros interesados se lo exige como un aspecto esencial del buen gobierno corporativo. En los últimos tiempos el origen ético de la adopción de un compliance se ha visto incluso reforzado con la asignación de un valor económico, pues los diversos ordenamientos legales imponen ahora a las

20 Vid., Engelhart, Marc, cit. (n. 12), p. 49.

21 Vid., en este sentido, Sieber, Ulrich, Compliance-Programme im Unternehmensstrafrecht, en SIEBER, Ulrich - DANNECKER, Gerhard - KINDHÄUSER, urs - VOGEL, Joachim - Walter, Tonio (Hrsg.), Festschrift für Klaus Tiedemann zum 70. Geburtstag, (Köln, Carl Heymanns, 2008), p. 455.

22 Destaca Bock, Dennis, Criminal Compliance (Baden-Baden, Nomos, 2011), p. 205, su falta de carácter jurídico. En esta misma línea, Agudo/Marco/Acero, Código de buen gobierno corporativo: Un análisis comparativo. Especial incidencia en el caso español, en Aposta Revista de Ciencias Sociales 46 (2010), p. 2, señalan que el código de buen gobierno está formado por recomendaciones o sugerencias. 
empresas el deber de informar al mercado si lo han hecho o no (comply or explain $)^{23}$. El que la empresa ajuste su actuación a la legalidad deja de ser, por lo tanto, un tema estrictamente ético para adquirir también una significación económica ${ }^{24}$.

Es oportuno destacar aquí que los incentivos adicionales para que las empresas adopten un programa de cumplimiento normativo no se han quedado en la obligación de informar de ello a los inversores como un elemento de juicio que influye decisivamente en el valor de cotización de sus acciones o títulos. El que la empresa haya implementado un sistema de cumplimiento normativo ha comenzado a ser tenido en cuenta también en la imposición misma de sanciones jurídicas, tal como lo atestigua un breve repaso a la legislación de los países que más se preocupan por controlar adecuadamente los riesgos provenientes de la actividad de las corporaciones.

En los EE.UU., por ejemplo, se tomó la decisión legislativa, por medio de las US Federal Sentencing Guidelines de 1991, de dar relevancia jurídicopenal a la incorporación de un programa de cumplimiento normativo como criterio de determinación de la pena a las empresas ${ }^{25}$. Iniciado el presente siglo, el sistema jurídico americano ha dado un paso más en la atribución de relevancia jurídica al compliance, pues ya no sólo repercute en la imposición de las sanciones penales, sino que incluso su falta de adopción o la inobservancia de ciertos parámetros legalmente definidos sobre su estructuración, pasan a ser pasibles de sanción. Este cambio de perspectiva se ha consolidado en la primera reacción legal frente a los escandalosos fraudes cometidos por importantes corporaciones a través de estados financieros falseados, esto es, la Sarbanes-Oxley Act (SOX) de 2002. Con una innegable impronta intervencionista, esta normativa apunta a asegurar el comportamiento ético y el mejoramiento de las prácticas de autogobierno en las empresas por medio de una labor de definición de los programas de cumplimiento normativo que las empresas deben obligatoriamente adoptar ${ }^{26}$. La tendencia a exigir legalmente de las

${ }^{23}$ Vid., en general sobre este tratamiento legal de los códigos de buen gobierno corporativo en diversos países, Agudo/Marco/Acero, cit. (n. 22), p. 13 y ss. En relación a la regulación española BACIGALUPO ZAPATER, Enrique, "Compliance" y derecho penal (Buenos Aires, Hammurabi, 2012), p. 11.

${ }^{24}$ Así, Bacigalupo Zapater, Enrique, cit. (n. 23), p. 46.

25 Vid., BAER, Miriam, Governing corporate compliance, en Boston College Law Review 50 (2009), p. 964; Rotsch, Thomas, en Achenbach, Hans - RansieK, Andreas (Hrsg.), Handbuch Wirtschaftsstrafrecht (3. Aufl., Heidelberg, C.F. Müller, 2012), 1. Teil, 4, n.m. 13.

${ }^{26}$ Vid., con mayor detalle, ImPerato, Gabriel, Corporate Crime and Compliance. What does the Government Expect?, en Corporate Counsel Review Vol. XXIV (November 2005) 2, p. 346 y s. Califica a la SOX como un modelo de vigilancia 
empresas la implementación de programas de cumplimiento normativo ha sido reiterada en la Dodd-Frank Wall Street Reform and Consumer Protection Act del 2010 que exige a las entidades financieras de riesgo sistémico el establecimiento de programas internos de cumplimiento de la normativa federal ${ }^{27}$.

En Europa, puede apreciarse, por su parte, un giro similar en el tratamiento jurídico de los programas de cumplimiento normativo adoptados por las empresas. La crisis económica del 2007 tuvo como una de sus principales causas la realización de excesos o irregularidades por parte de empresas en un mercado financiero desregulado ${ }^{28}$, lo que ha llevado a que, en muchos países europeos, haya aumentado la tendencia a aprobar normas especiales para exigirles, bajo amenaza de sanción, la adopción de sistemas de prevención de riesgos e indicar los requisitos que tales sistemas deben tener para poder exonerarles de responsabilidad ${ }^{29}$. La manera en la que se regula la responsabilidad penal de las personas jurídicas, implementada en los últimos años de manera generalizada en los distintos países europeos, es la prueba más clara de la asunción de esta perspectiva en la valoración jurídica del compliance corporativo.

\section{La responsabilidad penal de las personas juridicas}

Hasta hace pocas décadas, la responsabilidad penal de las personas jurídicas apenas encontraba reconocimiento en los países deudores de la tradición europea continental. Si se cometía un delito en la actividad empresarial, la responsabilidad penal recaía únicamente en sus miembros individuales, pero no en la persona jurídica, la que, en todo caso, sólo podía ser sancionada administrativamente. La situación comenzó a cambiar, sin embargo, en la década de los ochenta del siglo pasado a raíz de una recomendación de la entonces Comunidad Europea sobre la necesidad de

y control, BACKer, Larry, Surveillance and control: Privatizing and nationalizing corporate monitoring after Sarbanes-Oxley, en Michigan State Law Review, 1 (2004), p. 15 y s. Sobre algunas de las medidas más saltantes de la SOX, vid., BussmanN/ MATSCHKE, Der Einfluss nationalen Rechts auf Kontroll- und Präventionsmaßnahmen von Unternehmen, en Wistra 3 (2008), p. 89 y ss.

27 Vid., al respecto, González de LeÓn Berini, Arturo, El criminal compliance en la reforma norteamericana de la Dood-Frank Act, en SiLVA SÁnCHEZ, Jesús María (dir.), Criminalidad de empresa y Compliance (Barcelona, Atelier, 2013), p. 131 y ss.

${ }^{28}$ Así, Bacigalupo Zapater, Enrique, cit. (n. 23), p. 12; González de LeÓN Berini, Arturo, cit. (n. 27), p. 78 y s.

${ }^{29}$ Así, Gómez-Jara Díez, Carlos, Aproximación a la influencia del "gobierno corporativo" sobre el Derecho penal económico, en BAjo FERnÁndez, Miguel (dr.), Gobierno Corporativo y Derecho penal (Madrid, Editorial Universitaria Ramón Areces, 2008), p. 154. 
sancionar penalmente a las personas jurídicas para proteger los intereses económicos comunitarios. Desde entonces la responsabilidad penal de las personas jurídicas ha tenido una marcha triunfal en los países europeos y en su órbita de influencia como es, sin duda, el caso de los países latinoamericanos. Si bien no hay uniformidad al momento de decidir por qué delitos respondería penalmente una persona jurídica, la tendencia apunta a incluir el delito de corrupción. Esto seguramente por la adhesión de muchos países a los distintos instrumentos internacionales que imponen a los Estados parte la obligación de tomar medidas específicas contra la corrupción.

A diferencia del esquema simplista que inicialmente se manejó en los países del common law, la responsabilidad penal de las personas jurídicas asumida en los países deudores del sistema continental europeo no se sustenta en una identificación de la persona natural que comete el delito con la empresa en cuya representación actúa o en una simple responsabilidad vicarial, sino en una defectuosa organización de la persona jurídica misma. La manera como dicho defecto en la organización se expresaría es la falta de incorporación de un programa de cumplimiento normativo idóneo para prevenir la realización de infracciones penales. Por lo tanto, si, con anterioridad al delito, la persona jurídica cuenta con un compliance penal idóneo, entonces no se le podrá responsabilizar penalmente por el delito cometido.

Lo usual ha sido incluso que la regulación penal establezca los criterios para determinar la idoneidad del sistema de cumplimiento normativo. En el caso de la regulación penal peruana, se establece, por ejemplo, los siguientes requisitos que debe tener dicho programa: i) una persona u órgano nombrado por la persona jurídica que ejerza la función de auditoría interna de prevención con recursos y personal para cumplirla adecuadamente; ii) medidas preventivas que identifiquen las actividades o procesos de la persona jurídica que generen o incrementen los riesgos de comisión de delitos de cohecho activo trasnacional, establezcan los procesos específicos que permitan prevenir la realización de estos delitos, identifiquen los procesos de administración y auditoría de los recursos financieros que permitan su utilización en la comisión de estos delitos, y que instauren sistemas de denuncia que protejan al denunciante y permitan la detección y sanción interna de los trabajadores o directivos que incumplan el modelo de prevención; y iii) un mecanismo de difusión y supervisión interna del modelo de prevención.

\section{Sintesis}

La confluencia de las tres tendencias sobre la prevención de las conduc- 
tas de corrupción por parte de las empresas lleva a la siguiente conclusión sintética. En las legislaciones actuales de los países deudores del sistema continental europeo, lo usual no es que se les imponga directamente a las empresas el deber jurídico penalmente reforzado de implementar un programa de cumplimiento normativo para prevenir o, en su defecto, detectar los actos de corrupción de funcionarios públicos (AC-Compliance). Sin embargo, si la empresa adopta uno que sea idóneo, quedará exenta de la responsabilidad penal que le pudiera corresponder por el delito de corrupción cometido por su administrador, representante o dependiente. Incluso el que se proceda a adoptar un AC-Compliance luego de cometido el delito de corrupción, es considerado una circunstancia de atenuación de la responsabilidad penal.

\section{EL PROCESO DE ADOPCIÓN DE UN AC-COMPLIANCE}

La adopción de un compliance anticorrupción es un tema operativo que debe ser llevado a cabo correctamente, si es que se quiere asegurar el efecto exoneratorio de la responsabilidad penal. En efecto, si es que el sistema de cumplimiento normativo en materia anticorrupción no es implementado en la empresa de manera adecuada, entonces no se podrá sostener que ésta se encuentra debidamente organizada o que sus directivos han cumplido cabalmente con su deber de control o supervisión. Importante es, por lo tanto, determinar cómo debe instituirse este compliance para que sea idóneo.

Los escritos especializados destacan la complejidad de la labor de implementar un sistema de cumplimiento normativo en la empresa, pero reconocen que no existe un procedimiento legalmente establecido o un estándar uniforme para llevarlo a cabo ${ }^{30}$. Ante esta indefinición lo razonable es orientar dicha labor a la mejor consecución de los objetivos centrales de sistema de cumplimiento normativo en materia penal: Evitar la realización de las infracciones penales y detectar aquellas que, pese a las medidas de prevención, se hayan cometido. Con la mirada puesta precisamente en estos objetivos, se recomienda que el compliance se estructure sobre tres columnas fundamentales.

La primera columna consiste en formular un programa de cumplimiento, esto es, el cuerpo normativo que recoge los procedimientos empresariales internos de gestión de los riesgos de infracción penal ${ }^{31}$. Tres

30 Así, Campos Nave, José, Rechtsstaatliche Regeltreue? Corporate Compliance als zwingende Antwort des freiheitsliebenden Unternehmes im Wirtschaftsstrafrecht, (Frankfurt a.M., Peter Lang, 2011), p. 92.

31 Vid., Coca Vila, Ivó, cit. (n. 8), p. 60. 
pasos deben darse para ello: identificar los riesgos de infracción penal que se derivan usualmente de la actividad empresarial concretamente realizada (risk assessment), definir la manera como debe actuarse frente a los riesgos identificados (risk management) e instaurar dentro de la empresa una estructura propia para esta administración de los riesgos detectados (en especial el nombramiento de un compliance officer). La segunda columna es la implementación del programa de cumplimiento normativo en la empresa. Para materializar esta segunda columna igual se requiere dar tres pasos: informar a cada uno de los miembros de la empresa sobre el programa de cumplimiento normativo, incentivar por distintos medios idóneos su observancia y asegurar su efectiva vigencia por medio de diversas medidas organizativas. La tercera columna es el mantenimiento del programa de cumplimiento a pesar de su inobservancia por los trabajadores de la empresa en supuestos concretos. Esto precisa, por un lado, detectar la inobservancia (internal investigation) y, dado el caso, imponer las sanciones correspondientes $^{32}$. Pero resulta necesario también, por otro lado, que se proceda a la reformulación de aquellos puntos del programa que se han mostrado como inadecuados o insuficientes.

Donde resaltan más los aspectos propios de un AC-Compliance es, sin duda, en la identificación y administración de los riesgos de comisión de delitos de corrupción de funcionarios públicos. Lo primero permite identificar las fuentes de riesgo existentes o que pueden esperarse (análisis de riesgo), lo que supone determinar qué conductas de los miembros individuales de la empresa podrían configurar un delito de corrupción de funcionario público (¿qué?), así como los factores que promueven dichas conductas indebidas (¿por qué?). Una vez que se han identificado las fuentes de riesgo y ponderado sus causas, la empresa deberá establecer las medidas que deben adoptarse para prevenirlos adecuadamente (administración del riesgo).

\section{El análisis de riesgo (risk assessment)}

Es hoy una idea absolutamente consolidada que no hay manera de adoptar un sistema de cumplimiento normativo en materia anticorrupción si es que no se hace primeramente un análisis de riesgo. Por ejemplo, la Guía de Consulta para la FCPA elaborada por el DOJ y la SEC establece que un rasgo distintivo de un programa de cumplimiento efectivo es el análisis de riesgo, señalando de manera expresa que este paso resulta fundamental para el desarrollo de un programa de cumplimiento sólido ${ }^{33}$.

32 Vid., Gómez-Jara Díez, Carlos, cit. (n. 11), p. 116.

${ }^{33}$ Vid., Global Overview of Anti-Bribery Laws, Baker \& McKenzie, Jiménez-Gusi 
Lo mismo se indica en aquellas legislaciones que sancionan a las personas jurídicas por actos de corrupción y admiten la posibilidad de exonerarlas de responsabilidad penal por la adopción de un compliance anticorrupción. La ley chilena sobre la responsabilidad penal de las personas jurídicas establece, por ejemplo, que "el encargado de prevención del delito debe tener como competencia la identificación de las actividades o procesos de la entidad, sean habituales o esporádicos, en cuyo contexto se genere o incremente el riesgo de cometer delitos" que dan lugar a la responsabilidad penal de la persona jurídica. Por su parte, la ley peruana de responsabilidad de las personas jurídicas dispone que "el modelo de prevención debe contener como minimo medidas preventivas que identifiquen las actividades o procesos de la persona jurídica que generen o incrementen los riesgos de comisión de delitos de cohecho (...)".

Lo que, por el contrario, no parece tan claro es el enfoque que debe seguirse para hacer el análisis del riesgo. Lo usual ha sido asociarlo al trabajo de los auditores ${ }^{34}$, lo que resultaría lógico si se tratase de analizar riesgos económicos, pero no tanto si lo que se busca es analizar riesgos de infracción penal que requieren una labor de identificación de las formas de conducta que puedan subsumirse en tipos penales (en lo que aquí interesa, en los delitos de cohecho de funcionarios públicos en sus diversas modalidades o en delitos emparentados como el tráfico de influencias, la colusión desleal, la negociación incompatible, entre otros). Esta labor, lejos de responder a un orden administrativo de los procesos internos de la empresa, está referida fundamentalmente a la prevención situacional de delitos de corrupción de funcionarios públicos. Por ello, no deja de tener razón la afirmación hecha por un sector de la doctrina penal de que el análisis de riesgos de infracción penal es una actividad multidisciplinar que precisa de la intervención de un criminólogo y un penalista ${ }^{35}$. Mientras el primero identifica las formas de conducta en las que se establece una relación indebida con los funcionarios públicos, sus factores contributivos, la probabilidad de realización, la extensión del daño, etc.; el segundo indica las normas penales que las formas de conducta detectadas por el criminólogo infringirían y las consecuencias jurídico-penales que cabe esperar. Como puede verse, lejos de tratarse de riesgos en el manejo económico de la empresa, lo que se identifica son riesgos jurídicos que tienen un lado

(ed) (Pamplona, Aranzadi, 2015), p. 552.

34 Vid., González Franco/Schemmel/Blumenberg, La función del penalista en la confección, implementación y evaluación de los programas de cumplimiento, en ARROyo Zapatero, Luis/Nieto Martín, Adán (dr.), El Derecho penal económico en la era del Compliance (Valencia, Tirant lo Blanch, 2013), p. 160.

35 En este sentido, Nieto Martín, Adán, cit. (n. 2), p. 154. 
empírico del que se ocupa el criminólogo y otro normativo que debe ser definido por el penalista.

El análisis de riesgo consta de los siguientes pasos:

a) La fijación del objeto. Lo primero que debe determinarse es la actividad de la empresa en la que se van a identificar los riesgos de comisión de delitos de corrupción de funcionarios públicos ${ }^{36}$. Una de las características de esta labor de identificación es que sea concreta, lo que supone entrar en las actividades específicamente desplegadas por la empresa. Si bien los riesgos pueden provenir de cualquier miembro de la empresa, es lógico que el caso de la corrupción se circunscriba a las actividades en las que exista contacto con funcionarios públicos, como, por ejemplo, la presentación de solicitudes a instituciones públicas, la obtención de permisos administrativos, la representación en procesos administrativos y judiciales, la realización de actividades supervisadas por organismos públicos, etc.

b) La identificación de las posibles infracciones penales. El segundo paso es identificar qué comportamientos subsumibles en delitos de corrupción pueden presentarse en la actividad de la empresa en la que se centra el análisis. Estos comportamientos se derivan, por lo general, de las particularidades propias de la actividad desplegada por la empresa (por ejemplo, la necesidad de obtener permisos administrativos por compañías constructoras o el sometimiento a la supervisión permanente de una entidad estatal por participar en mercados regulados) o de su concreta estructura organizativa (por ejemplo, la ausencia de controles internos sobre la actuación de los empleados, el monopolio de un trabajador en el contacto con el funcionario público o la existencia de cajas negras en la contabilidad de la empresa).

La identificación de las formas de actuación penalmente relevante debe ser también concreta. Por ello, se recomienda la utilización de ejemplos de los grupos de casos más frecuentes ${ }^{37}$. No solamente debe identificarse la forma de actuación que constituye un riesgo de comisión de un delito de corrupción de funcionario público, sino también los integrantes de la empresa que están expuestos a dicho riesgo ${ }^{38}$. No es necesario identificar

${ }^{36}$ El deber de prevención de la empresa no es absoluto, sino que depende del giro de la organización, como lo indica Artaza Varela, Osvaldo, Programas de cumplimiento. Breve descripción de las reglas técnicas de gestión del riesgo empresarial y su utilidad jurídico-penal, en Hortal, Juan - VAliente, Vicente (coord.), Responsabilidad de la empresa y Compliance, Programas de prevención, detección y reacción penal, (Buenos Aires, BdeF, 2014), p. 250.

${ }^{37}$ Gallego Soler, Ignacio, Criminal compliance y proceso penal: Reflexiones iniciales, en Hortal, Juan - Valiente, Vicente (coord.), Responsabilidad de la empresa y Compliance. Programas de prevención, detección y reacción penal (Buenos Aires, BdeF, 2014), p. 206.

38 Vid., Artaza Varela, Osvaldo cit. (n. 36), p. 251. 
todas las posibles formas de comportamiento penalmente relevante que abstractamente puedan presentarse en la actividad analizada de la empresa; aquí es posible establecerse un primer filtro que deje de lado aquellas que son muy remotas. Así mismo, en la identificación de los riesgos se pueden delimitar los llamados campos de riesgo (Risikofelder), esto es, los lugares específicos de la empresa en los que ciertos riesgos de infracción legal usualmente aparecen ${ }^{39}$.

Para llevar a cabo la labor de identificación de los riesgos de comisión de un delito de corrupción de funcionario público, cabe acudir a diversas fuentes que proporcionen un conocimiento integral de las actuaciones empresariales que pueden llegar a tener relevancia penal. Estas fuentes de información pueden tener una procedencia interna o externa. Dentro de las fuentes internas cuentan los registros internos sobre incidentes anteriores, informes de auditoría, entrevistas con directivos, trabajadores o con terceros vinculados (como proveedores o consumidores), o encuestas a trabajadores. En relación con esta última fuente de información, pueden usarse para los delitos de corrupción dos tipos de encuestas: el autoinforme (asegurando la confidencialidad, se pregunta por los actos de corrupción que el trabajador ha cometido) y la encuesta de percepción delictiva (encuestas de opinión sobre la percepción de que la actividad de la empresa se lleve a cabo con actos de corrupción $)^{40}$. Es recomendable que las empresas coloquen en los contratos de trabajo el derecho del empleador a recabar información sin violentar, claro está, derechos constitucionales como el nemo tenetur. Como fuentes externas pueden mencionarse los estudios sobre el mercado o el sector específico en el que se desenvuelve la empresa (hay mercados más riesgosos que otros), las comunicaciones o directivas de las instancias administrativas de control (contraloría, OCIs, etc.) o los pronunciamientos jurisprudenciales pertinentes ${ }^{41}$.

\section{c) La evaluación del riesgo}

Identificadas las posibles conductas constitutivas de corrupción de funcionarios públicos en el sector o actividad analizada de la empresa, el paso siguiente es la evaluación de dichos riesgos. Lo que se hace es una valoración de los riesgos detectados en función de su clase, frecuencia, extensión de los posibles daños, etc. ${ }^{42}$. De lo que se trata es de tener determinadas todas las particularidades relevantes de cada riesgo para elaborar una escala de

39 Vid., Bock, Dennis, cit. (n. 22), p. 590.

${ }^{40}$ Nieto Martín, Adán, cit. (n. 2), p. 159 y s.

${ }^{41}$ Vid., Bock, Dennis, Strafrechtliche Aspekte der Compliance-Diskussion - $\$ 130$ OWiG als zentrale Norm der Criminal Compliance, en ZIS 2 (2009), p. 76; EL MisMO, cit. (n. 22), p. 591.

${ }^{42}$ En este sentido, Engelhart, Marc, cit. (n. 12), p. 713. Precisa Bock, Dennis, 
los mismos ${ }^{43}$. Esta escala se hace teniendo en cuenta la importancia de los riesgos, lo cual se determina, por lo general, en función de dos factores: la probabilidad de realización y el impacto potencial.

La probabilidad de realización de los riesgos identificados se puede determinar por medio de un método cuantitativo o cualitativo. Como no hay un único modelo de cuantificación, si se opta por emplear una escala cuantitativa, se debe establecer con claridad cuáles son los criterios de cuantificación que se van a usar para determinar la probabilidad de los riesgos identificados. Lo usual, sin embargo, es acudir a una escala cualitativa simple como, por ejemplo: alto, medio o bajo (HML-score). Para llegar a definir la probabilidad del riesgo, se pueden tener en cuenta los siguientes criterios: i) el historial de infracciones de la empresa o de otras del sector: Este historial no debe limitarse a las que llegaron al conocimiento de las autoridades penales, sino que debe incluir también aquellas que, por alguna razón, no fueron perseguidas (falta de detección, soluciones extraprocesales, etc.). Del mismo modo, debe tenerse en consideración las llamadas "familias de infracciones", en la medida que puedan poner en evidencia un riesgo que todavía no se ha materializado (por ejemplo, infracciones disciplinarias de funcionarios públicos); ii) las estimaciones subjetivas: Dada la experiencia de los directivos y empleados, resulta conveniente preguntarles mediante entrevistas o encuestas sobre el grado de probabilidad que ellos estiman de aparición de las infracciones penales detectadas; iii) los controles de mitigación: Se trata de determinar los controles de los que dispone la empresa frente al riesgo detectado. Estos controles pueden ser específicos o generales. Está claro que la probabilidad del riesgo inherente a una actividad se reduce si cuenta con controles de mitigación eficaces, quedando únicamente lo que se conoce como riesgo residual. Por ello, debe analizarse la efectividad de los controles implementados en la empresa, pues muchas veces los controles no son más que letra muerta, dando la apariencia de una poca probabilidad que, en realidad, es alta.

El criterio cualitativo del impacto del riesgo se puede determinar, por su parte, a partir de los siguientes criterios: $i$ ) la naturaleza del daño producido (importancia del bien jurídico protegido) y la gravedad de la conducta realizada (grado de afectación del bien jurídico); ii) la incidencia de la infracción cometida en los objetivos económicos y estratégicos de la empresa, y iii) la utilidad social de la actividad riesgosa desarrollada por la empresa.

cit. (n. 41), p. 76, que en relación con este proceso de valoración de los riesgos se discute cuáles son los criterios de valoración y el método para prever su aparición.

${ }^{43}$ Así, EngelHart, Marc, cit. (n. 12), p. 713. 
Con base en la evaluación de los riesgos realizada con los criterios de la probabilidad y el impacto potencial, se decide la necesidad de actuar para prevenirlos, así como la intensidad de la prevención. Debe hacerse aquí la pertinente indicación de que la probabilidad del descubrimiento y de la persecución de la infracción penal, no pueden ser tomadas como criterios con los cuales decidir sobre la necesidad de adoptar las medidas de prevención correspondientes.

d) Revisión. En razón de la variabilidad de las circunstancias que pueden dar lugar a hechos que configuren una infracción penal, así como de las eventuales modificaciones del derecho vigente y los criterios de interpretación jurídica, resulta recomendable que se haga una revisión continua de la labor de identificación de los riesgos ${ }^{44}$. Es necesario conocer lo antes posible nuevos riesgos o la intensificación de los ya existentes ${ }^{45}$. Por ello, puede decirse que el análisis de riesgos no es un proceso único, sino que precisa de la evaluación e iteración en forma de una ininterrumpida vigilancia ${ }^{46}$. Esta revisión puede ser ordinaria (una vez al año, por ejemplo) o por situaciones detonantes como el ingreso a nuevos mercados, una fusión $\mathrm{o}$ adquisición, etc.

\section{La administración del riesgo (risk management)}

El proceso de análisis de riesgos debe materializarse en la elaboración de una matriz, mapa o inventario de riesgos (liability inventory) ${ }^{47}$, en el que debe constar la evaluación de los riesgos detectados. En correspondencia con los criterios utilizados en la evaluación, la matriz está compuesta por dos vectores, uno de probabilidad y otro de impacto. Con base en esta información, se lleva a cabo la labor de administración del riesgo, la que apunta a tomar las medidas idóneas para reducir el riesgo detectado a lo jurídicamente tolerable y, en caso ello no sea posible, a detectarlo para poder gestionar sus efectos lesivos. La idoneidad preventiva de estas medidas está en función de la eliminación de los factores que originan las formas de comportamiento que se pueden subsumir en un tipo penal de corrupción de funcionarios públicos. Cuáles son las medidas de prevención o gestión que debe implementar la empresa en materia anticorrupción, no están fijadas detalladamente en las leyes o reglamentos. Sin embargo, existen

${ }^{44}$ Así, Bock, Dennis, cit. (n. 22), pp. 595, 742.

${ }^{45}$ Coca Vila, Ivó, cit. (n. 8), p. 57.

46 Vid., BocK, Dennis, Compliance y deberes de vigilancia en la empresa, en Kuhlen, Lothar - Montiel, Juan Pablo - Ortiz de Urbina, Ínigo (eds.), Compliance y teoría del Derecho penal (Madrid, Marcial Pons, 2013), p. 114.

47 Vid., Engelhart, Marc, cit. (n. 12), p. 713; Bock, Dennis, cit. (n. 41), p. 76; El Mismo, cit. (n. 22), p. 589; Nieto Martín, Adán, cit. (n. 2), p. 152. 
lineamientos referenciales que dan cuenta de las medidas más adecuadas, como los elaborados por el Ministerio de Justicia en los Estados Unidos $o$ en el Reino Unido, o los difundidos por diversas instituciones internacionales que se ocupan de este tema como es el caso de transparencia internacional o la OCDE.

a) Códigos de conducta. En la primera línea de la administración del riesgo se suele colocar al código de conducta, esto es, aquel instrumento en el que, desde la dirección de la empresa (tone from the top), se plasma la indicación de los parámetros normativos que deben ser observados por los trabajadores. No se trata simplemente de repetir lo que dice la ley ${ }^{48}$, sino de precisar aquello que el trabajador de la empresa no debe hacer. Se debe contar con criterios específicos que orienten el comportamiento concreto de cada miembro de la empresa hacia la evitación del riesgo de prácticas corruptivas. Dado el carácter internacional de la lucha contra la corrupción, este código de conducta puede ser común para todos los países en los que la empresa desarrolla sus actividades (lo que exige ciertamente una mayor amplitud de las conductas relevantes).

En los códigos de conducta (que, en materia de corrupción, se conocen también como políticas anticorrupción) debe dejarse claro una tolerancia cero en materia de corrupción. Esta orientación definida hace que no solamente se proscriban de manera absoluta las conductas de pagar una coima a un funcionario público (incluidos los pagos de engrase o facilitamiento que, incluso a nivel de la corrupción internacional, están perdiendo su anterior permisividad ${ }^{49}$ ), sino también restringir otras que se aproximan a dicha situación de riesgo ${ }^{50}$. Como ejemplos de estas últimas conductas riesgosas pueden mencionarse las siguientes: $i$ ) el mecenazgo o esponsorización: Se trata de la entrega de contribuciones para fines sociales, culturales o deportivos. Como se sabe muy bien, la ventaja indebida del delito de cohecho no tiene que estar necesariamente dirigida al funcionario público, por lo que el sponsoring podría albergar, bajo determinadas condiciones, una corrupción encubierta. Por ello, estos pagos deben ser transparentes, lo que se consigue si se formalizan documentalmente y se hacen en el marco de un convenio con objetivos claros. En ningún caso, la esponsorización debe estar vinculada a un comportamiento del funcionario público. Debe asegurarse la honorabilidad o solvencia moral de la entidad subvencionada; ii) el financiamiento de partidos políticos: Si bien no hay una prohibición absoluta para realizar aportes a los partidos políticos, deben tomarse diver-

${ }^{48}$ Así, con referencias a la jurisprudencia americana e italiana, NiEto Martín, Adán, cit. (n. 2), p. 354.

49 Vid., al respecto, Nieto Martín, Adán, cit. (n. 2), p. 329 y ss.

50 Nieto Martín, Adán, cit. (n. 1), p. 203. 
sos recaudos para evitar que se pueda generar la idea de un compromiso del candidato con los intereses del donante. Uno de esos recaudos es indudablemente la cantidad del aporte. Por ello, es la misma regulación electoral la que establece unos límites cuantitativos a los aportes. Estos límites deben ser estrictamente observados no sólo en el caso de aportes directos, sino también de los indirectos, esto es, los realizados por intermediarios o a través de empresas controladas; iii) las atenciones o regalos a funcionarios públicos: Es necesario que cualquier atención a un funcionario público se mueva en el marco de lo socialmente adecuado. El valor del regalo es un criterio fundamental para poder afirmar su adecuación social, por lo que deben establecerse límites generales y prohibiciones específicas en el caso de funcionarios públicos cuyo ámbito de decisión repercuta directamente en los intereses de la empresa; iv) las rebajas sustanciales en los servicios o bienes ofrecidos: Este comportamiento está estrechamente vinculado a las atenciones o regalos, aunque no revista tal forma. Está claro que no se refiere a aquellos descuentos de carácter comercial que son aplicables a cualquier cliente, sino a los que se otorgan a personas especiales como socios, trabajadores, etc.; $v$ ) los gastos de viaje para visitas del funcionario a las fábricas o instalaciones: Lo primero que debe decirse es que estos gastos no se encuentran prohibidos per se, pero su materialización debe hacerse bajo ciertas condiciones. Así, deben ser, por un lado, proporcionales al fin que se pretende conseguir, de manera tal que se excluya un exceso a favor del funcionario público. Por otro lado, deben también ser pagados directamente por la empresa, nunca a través del funcionario público por medio de un adelanto, reembolso o compensación.

Un punto importante en la elaboración de las políticas anticorrupción es que no deben limitarse a indicar la forma como debe tener lugar la relación con los funcionarios públicos, sino que tienen que hacer referencia también a los valores que inspiran dicha actuación ${ }^{51}$. La orientación ética

${ }^{51}$ En este sentido, Nieto Martín, Adán, cit. (n. 7), p. 6, pone de manifiesto que la empresa solamente puede garantizar que sus miembros cumplan con la ley, si consigue que éstos asuman los valores éticos en los que descansa la regulación estatal. En la literatura norteamericana, PAINE, Lynn, Managing for Organizational Integrity, en Harvard Business Review, (Mar.-Apr. 1994), p. 110 y s., distingue los programas basados en el cumplimiento y los programas basados en la integridad, en tanto los primeros se enfocan en la intimidación por medio del castigo por su infracción, los segundos se centran en la interiorización de valores organizacionales en los trabajadores de la empresa. Pese a esta distinción, nada impide que el programa de cumplimiento acuda a ambas formas de ordenación del comportamiento [vid., así, WeLlNER, Philip, Effective compliance programs and corporate criminal prosecutions, en Cardozo Law Review 27 (2005), p. 513]. Específicamente para los AC-Compliance Nieto Martín, Adán, cit. (n. 2), p. 354. 
del comportamiento, además de darle sentido a la actuación concretamente prevista, tiene la ventaja de ofrecer parámetros de decisión a los miembros de la empresa en aquellos ámbitos en los que la regulación no determina concretamente el curso correcto de la acción ${ }^{52}$. Por otro lado, no basta con la mera enunciación de valores, sino que es necesario que la organización cuente con estructuras que se ajusten realmente a dichos valores ${ }^{53}$.

b) Medidas de prevención. La administración del riesgo no se queda en la elaboración de políticas anticorrupción, sino que cabe adoptar también otras medidas orientadas a asegurar que los miembros de la empresa no puedan llevar a cabo prácticas corruptas en determinados contextos de actuación. Estas medidas pueden ser esquematizadas como de la siguiente forma:

i) Medidas de control sobre el uso del patrimonio de la empresa. Dado que el acto de corrupción se expresa, por lo general, en el pago de una coima o prebenda, no hay duda sobre la necesidad de tomar medidas que apunten a impedir que se use el patrimonio de la empresa para ello. Son diversas las medidas de control que pueden tomarse al respecto.

En primer lugar, está el control de los regalos a funcionarios públicos, lo que se debe expresar en el establecimiento de límites a su permisión discrecional, necesidad de autorización y los casos de prohibición total. No deben otorgarse a funcionarios que están próximos a emitir una decisión o realizan una labor continua de supervisión, así como tampoco tener un carácter sistemático. Para una mayor transparencia, lo conveniente es contar incluso con un registro de regalos a funcionarios públicos, en los casos que se encuentren autorizados.

En segundo lugar, deben suprimirse o controlarse las cajas con dinero en efectivo, pues lo usual es que el pago de una coima se haga en efectivo, lo que se dificulta si la empresa no procesa pagos de esta forma. Lo mismo debe hacerse en relación con el uso de tarjetas de créditos por los empleados para atenciones. De nada sirve una política estricta para regalos a funcionarios públicos, si éstos se pueden hacer por medio del uso de tarjetas de créditos de los empleados o directivos. Es necesario establecer una limitación de su uso y reglas estrictas de justificación.

La contratación de nuevo personal debe controlarse también para evitar que se utilice como favor a un funcionario público (la actividad contratada puede ser real o ficticia). Una medida idónea es asignar la función de contratar a persona distinta de la que solicita la plaza.

52 Así lo destaca Imperato, Gabriel, cit. (n. 26), p. 349.

53 Vid., con base en estudios empíricos, Eigenstetter, Monika, Werte oder Regeln? Einige Überlegungen zur Wirkung auf Motivation und Verhaltensintentionen, en ZIS 3 (2011), p. 129 y ss. 
A nivel contable, es fundamental el control para impedir la creación de cajas negras para pagos que no pueden estar reflejados en la contabilidad. Las cajas negras son fondos de la empresa que no aparecen en la contabilidad y a los que tienen acceso un grupo reducido de personas. No hay duda que la existencia de tales fondos ofrece a la empresa un medio idóneo para el pago de coimas o ventajas indebidas.

ii) Medidas de administración del personal. El control del personal es también importante de cara a evitar que se lleven a cabo actos de corrupción de funcionarios públicos, pues finalmente el pago de una coima se origina en la decisión de un trabajador o directivo. Dentro de las medidas de control del personal cabe destacar, por ejemplo, su capacitación para la identificación de las situaciones de riesgo de corrupción y el comportamiento que se debe seguir en dichas situaciones ${ }^{54}$. Esta capacitación puede ser más intensa en el caso de trabajadores que se encuentren en los campos de riesgo. El control en la contratación del personal es otra medida idónea, en especial en el caso de los puestos de riesgo, pues conlleva la adopción de criterios de selección que aseguren una línea de actuación contraria a la corrupción ${ }^{55}$. En este punto es importante destacar también el cuidado al contratar a ex altos directivos de la Administración, sobre todo en cuanto a la necesidad de respetar un periodo de enfriamiento. Otra medida aconsejable es la adopción de sistemas de rotación de personal en puestos de contacto con funcionarios públicos, lo que se hace con la finalidad de evitar el establecimiento de relaciones personales especiales que abran la puerta a posibles actos de corrupción ${ }^{56}$. Finalmente, en el caso de decisiones sensibles relacionadas con funcionarios públicos es conveniente el establecimiento de sistemas especiales de control como el principio de los cuatro ojos o la exigencia del refrendo para la toma de decisiones.

iii) Medidas de acceso a información relevante. La implementación de mecanismos de acceso a la información necesaria para la toma de una decisión correcta en el trato con un funcionario público, constituye igualmente una medida fundamental para evitar prácticas corruptivas. De entre los diversos mecanismos de acceso, cabe destacar especialmente la implementación de líneas de ayuda (help line) para el asesoramiento de los miembros de la empresa ${ }^{57}$. De esta manera, el miembro individual de la empresa estará en mejor posición de poder actuar de la manera más transparente en su trato con el funcionario público.

iv) El control de la honorabilidad de terceras partes (los asesores, proveedores

\footnotetext{
54 Vid., Nieto Martín, Adán, cit. (n. 2), p. 354.

55 Vid., Nieto Martín, Adán, cit. (n. 2), p. 355.

56 Vid., Nieto Martín, Adán, cit. (n. 2), p. 356.

57 Vid., Bock, Dennis, cit. (n. 22), p. 655 y ss.
} 
o partners de negocios). El control de la honorabilidad debe llevarse a cabo en todas las etapas de la relación contractual con los terceros (due diligen$c e$ ). A nivel precontractual, se exige sobre todo que los terceros cuenten también con políticas anticorrupción similares a las implementadas por la empresa, así como que pongan de manifiesto abiertamente sus vínculos con los funcionarios públicos correspondientes. A nivel contractual, los contratos deben estar formalizados y con expresa referencia a las actividades que se van a realizar, en donde se destaque el rechazo a toda forma de corrupción o actividades de riesgo con mecanismos de control y la inclusión de cláusulas de resolución contractual e indemnizatorias. En la etapa post contractual un papel importante cumple la efectivización de los pagos, los que deben estar debidamente documentados y justificados conforme a los términos del contrato ${ }^{58}$.

c) Medidas de detección. La gestión del riesgo de comisión de conductas de corrupción de funcionarios públicos no se agota en su prevención, sino que continúa si es que no se pudo evitar su realización. En este caso, lo que se tiene que conseguir con el programa de cumplimiento normativo es su oportuna detección y el emprendimiento de medidas internas y externas que contribuyan a reducir los efectos lesivos producidos ${ }^{59}$. Además de los mecanismos de control y supervisión generales (vigilancia de superiores, auditoría interna, etc.), se presenta como especialmente conveniente el establecimiento de un sistema de denuncias de irregularidades al interior de la empresa (whistle-blowing) ${ }^{60}$, con cuya ayuda todos los trabajadores podrán estar comprometidos en mantener un ambiente de respeto de la legalidad. Condiciones básicas para el funcionamiento del sistema de denuncia es que sea confiable para el trabajador ${ }^{61}$, así como también capaz de excluir eventuales denuncias falsas ${ }^{62}$. No hay ninguna razón para no

58 Vid., Nieto Martín, Adán, cit. (n. 2), p. 365.

59 En este sentido, Nieto Martín, Adán, cit. (n. 2), p. 355.

${ }^{60}$ Vid., con mayor detalle, Bock, Dennis, cit. (n. 22), p. 732 y ss. Una exposición general sobre el origen y desarrollo de este mecanismo empresarial de detección de irregularidades, RAGUÉS I VALLÈs, Ramon, Los procedimientos internos de denuncia como medida de prevención de delitos en la empresa, en SiLva SÁnchez, Jesús María (dir.), Criminalidad de empresa y Compliance (Barcelona, Atelier, 2013), p. 163 y ss.

${ }^{61}$ Destacan, en este sentido, Bock, Dennis, cit. (n. 41), p. 78; CocA VILA, Ivó, cit. (n. 8), p. 59; Bussmann/MatschKe, cit. (n. 26), p. 94, el anonimato del denunciante. Críticamente sobre el anonimato de las denuncias, RAGUÉS I VALLĖs, Ramon, cit. (n. 60), p. 181 y s., destacando, más bien, la garantía de la confidencialidad respecto de la identidad del denunciante.

${ }^{62}$ Así, Engelhart, Marc, cit. (n. 12), p. 716 y s.; Momsen, Carsten, Internal Investigations zwischen arbeitrechtlicher Mitwirkungspflicht und strafprozessualer Selbstbelastungsfreiheit, en ZIS 6 (2011), p. 509. 
extender el sistema de denuncias a personas ajenas a la organización empresarial (clientes, proveedores, etc.), en la medida en que estén también en capacidad de tomar conocimiento de actuaciones irregulares en el marco de la actividad empresarial ${ }^{63}$.

\section{BibLIOGRAFÍA}

Agudo/Marco/Acero, Código de buen gobierno corporativo: Un análisis comparativo. Especial incidencia en el caso español, en Aposta Revista de Ciencias Sociales 46 (2010), pp. 1-77.

Artaza Varela, Osvaldo, Programas de cumplimiento. Breve descripción de las reglas téenicas de gestión del riesgo empresarial y su utilidad jurídico-penal, en HORTAL, Juan - VAliente, Vicente (coord.), Responsabilidad de la empresa y Compliance, Programas de prevención, detección y reacción penal (Buenos Aires, BdeF, 2014), pp. 231-270.

Bacigalupo Zapater, Enrique, "Compliance" y derecho penal (Buenos Aires, Hammurabi, 2012).

BACKER, Larry, Surveillance and control: Privatizing and nationalizing corporate monitoring after Sarbanes-Oxley, en Michigan State Law Review, 1 (2004), pp. 1-114.

BAER, Miriam, Governing corporate compliance, en Boston College Law Review 50 (2009), pp. 949-1019.

Baker \& McKenzie, Jiménez-Gusi (ed), Global Overview of Anti-Bribery Laws, (Pamplona, Aranzadi, 2015).

Воск, Dennis, Compliance y deberes de vigilancia en la empresa, en KuHLEN, Lothar - Montiel, Juan Pablo - Ortiz de Urbina, Ínigo (eds.), Compliance y teoría del Derecho penal (Madrid, Marcial Pons, 2013), pp. 107-121.

Bоск, Dennis, Criminal Compliance (Baden-Baden, Nomos, 2011).

Воск, Dennis, Strafrechtliche Aspekte der Compliance-Diskussion - $\mathbb{S} 130$ OWiG als zentrale Norm der Criminal Compliance, en ZIS 2 (2009), pp. 68-81.

Bussmann/MatschKe, Der Einfluss nationalen Rechts auf Kontroll- und Präventionsmaßnahmen von Unternehmen, en Wistra 3 (2008), pp. 88-95.

Campos Nave, José, Rechtsstaatliche Regeltreue? Corporate Compliance als zwingende Antwort des freiheitsliebenden Unternehmes im Wirtschaftsstrafrecht (Frankfurt a.M., Peter Lang, 2011).

Carrión Centeno, Andy, Criminal Compliance (Lima, Thomson Reuters, 2014).

COCA VILA, Ivó, ¿Programas de cumplimiento como forma de autorregulación regulada?, en Silva Sánchez, Jesús María (dir.), Criminalidad de empresa y Compliance (Barcelona, Atelier, 2013), pp. 43-76.

Darnacullta i Gardella, Mercé, Autorregulación y Derecho Público: La autorregulación regulada (Madrid, Marcial Pons, 2005).

EigenstetTER, Monika, Werte oder Regeln? Einige Überlegungen zur Wirkung auf Motivation und Verbaltensintentionen, en ZIS 3 (2011), pp. 129-136.

63 Vid., Ragués I Vallès, Ramon, cit. (n. 60), pp. 161, 180; Rotsch, Thomas, cit. (n. 25), n.m. 54. 
EngelHart, Marc, Sanktionierung von Unternehmen und Compliance, 2a ed. (Berlin, Duncker \& Humblot 2012).

Esteve Pardo, José, Autorregulación: Génesis y efectos (Navarra, Aranzadi, 2002).

Gallego Soler, Ignacio, Criminal compliance y proceso penal: Reflexiones iniciales, en Hortal, Juan - Valiente, Vicente (coord.), Responsabilidad de la empresa y Compliance. Programas de prevención, detección y reacción penal (Buenos Aires, BdeF, 2014), pp. 195-226.

GOMEZ-JaRa DíEz, Carlos, Aproximación a la influencia del "gobierno corporativo" sobre el Derecho penal económico, en BAjo FernándeZ, Miguel (dr.), Gobierno Corporativo y Derecho penal (Madrid, Editorial Universitaria Ramón Areces, 2008), pp. 149-157.

Gómez-Jara Díez, Carlos, Fundamentos de la responsabilidad penal de las personas jurídicas, en Bajo, Miguel - Feijoo, Bernardo - Gómez-Jara, Carlos, Tratado de responsabilidad penal de las personas jurídicas (Madrid, Aranzadi, 2012), pp. 111-135.

GONZÁLEZ DE LEÓN BERINI, Arturo, El criminal compliance en la reforma norteamericana de la Dood-Frank Act, en Silva Sánchez, Jesús María (dir.), Criminalidad de empresa y Compliance (Barcelona, Atelier, 2013), pp. 131-142.

GonzÁlez Franco/Schemmel/Blumenberg, La función del penalista en la confección, implementación y evaluación de los programas de cumplimiento, en ARROYO ZAPATERo, Luis/Nieto Martín, Adán (dr.), El Derecho penal económico en la era del Compliance (Valencia, Tirant lo Blanch, 2013), pp.155-163.

Hefendehl, Roland, Corporate Governance und Business Ethics: Scheinberuhigung oder Alternativen bei der Bekämpfung dr Wirtschaftskriminalität?, en JZ 3 (2006), pp. 119-125.

Imperato, Gabriel, Corporate Crime and Compliance. What does the Government Expect?, en Corporate Counsel Review Vol. XXIV (November 2005) 2, pp. 345-357.

Maroto Calatayud, Manuel, Liberalismo versus neocorporativismo: Los discursos de la autorregulación como discursos legitimantes, en ARroYo, Luis - LASCANO, Carlos - Nieto, Adán (dir.), Derecho penal de la empresa (Buenos Aires, Ediar, 2012), pp. 413-441.

MOMSEn, Carsten, Internal Investigations zwischen arbeitrechtlicher Mitwirkungspflicht und strafprozessualer Selbstbelastungsfreiheit, en ZIS 6 (2011), pp. 508-516.

Nieto Martín, Adán, La prevención de la corrupción, en Nieto Martín, Adán (dir.), Manual de cumplimiento penal en la empresa (Valencia, Tirant lo Blanch, 2015), pp. 307-371.

Nieto MarTín, Adán, La privatización de la lucha contra la corrupción, en Arroyo Zapatero, Luis-Nieto Martín, Adán (directores), El Derecho penal económico en la era del compliance (Valencia, Tirant lo Blach, 2013), pp. 191-210.

Nieto Martín, Adán, La responsabilidad penal de las personas jurídicas: Un modelo legislativo (Madrid, Iustel, 2008).

NiETO MARTín, Adán, Responsabilidad social, gobierno corporativo y autorregulación: sus influencias en el derecho penal de la empresa, en Polít. crim. 5 (2008) A3-5, pp. 1-18.

PAINE, Lynn, Managing for Organizational Integrity, en Harvard Business Review, Mar.-Apr. 1994, pp. 106-117.

RAGUÉS I VALLÈS, Ramon, Los procedimientos internos de denuncia como medida de prevención de delitos en la empresa, en Silva Sánchez, Jesús María (dir.), Criminalidad de empresa y Compliance (Barcelona, Atelier, 2013), pp. 161-196.

Rotsch, Thomas, en Achenbach, Hans - RansieK, Andreas (Hrsg.), Handbuch Wirtschaftsstrafrecht, (3. Aufl., Heidelberg, C.F. Müller, 2012), 1. Teil, 4. 
SIEBER, Ulrich, Compliance-Programme im Unternehmensstrafrecht, en SIEBER, Ulrich - Dannecker, Gerhard - Kindhäuser, Urs - Vogel, Joachim - Walter, Tonio (Hrsg.), Festschrift für Klaus Tiedemann zum 70. Geburtstag (Köln, Carl Heymanns, 2008), pp. 449-484.

THeILE, Hans, Unternehmensrichtlinien - ein Beitrag zur Prävention von Wirtschaftskriminalität?, en ZIS 9 (2008), pp. 406-418.

WeLLnER, Philip, Effective compliance programs and corporate criminal prosecutions, en Cardozo Law Review 27 (2005), pp. 497-528. 